\title{
Influência do tipo de uso e ocupação do solo no assoreamento do reservatório Bom Jardim, Uberlândia-MG
}

\section{Influence of land use and occupation on the silting of Bom Jardim Reservoir, Uberlândia - MG}

Data de entrada: 28/02/2018

Data de aprovação: $04 / 12 / 2018$

Caroline Soler Martins $^{1 *}$ | Alessandra Campos dos Santos ${ }^{2}$ | José Eduardo Alamy Filho ${ }^{1}$

DOI: https://doi.org/10.36659/dae.2020.040

ORCID ID

Martins CS (1D) https://orcid.org/0000-0003-3907-179X
Santos AC (D) https://orcid.org/0000-0002-9322-8391

Filho JEA (D) https://orcid.org/0000-0001-5207-9396

\section{Resumo}

O assoreamento de reservatórios frequentemente reduz sua vida útil. Foram realizadas simulações da produção de sedimentos afluentes ao reservatório de abastecimento público Bom Jardim, em de Uberlândia (MG), por meio do software SWAT (Soil and Water Asscessment Tool), com o objetivo de avaliar a interferência do tipo de uso do solo no aporte de sedimentos do reservatório. Nas simulações aplicou-se o tipo de uso do solo e variouse a porcentagem de Agricultura substituída por Floresta. Verificou-se que quanto maior a porcentagem de Agricultura substituída por Floresta, menor a produção de sedimentos. Utilizou-se um programa para cálculo de assoreamento de reservatórios e concluiu-se que quanto maior o reflorestamento em áreas de Agricultura, menor é o assoreamento no reservatório.

Palavras-chave: Uso e Ocupação do Solo. Assoreamento. Reservatório Bom Jardim. SWAT.

\section{Abstract}

The silting of reservoir often reduces its life. Simulations about production of tributary sediments to the Bom Jardim public supply reservoir, in Uberlândia (MG), were performed through the SWAT software (Soil and Water Asscessment Tool), in order to evaluate the interference of the land use in the reservoir sediment supply. In the simulations, the type of land use was applied, and the percentage of Agriculture replaced by Forest was varied. It was verified that the higher the percentage of Agriculture replaced by Forest, the lower the sediment production. A program was used to calculate sedimentation of reservoirs and the conclusion is that the greater the reforestation in Agriculture areas, the lower the sedimentation in the reservoir.

Keywords: Land Use and Occupation. Silting. Bom Jardim Reservoir. SWAT.

\footnotetext{
${ }^{1}$ Universidade Federal de Uberlândia (UFU) - Uberlândia - Minas Gerais - Brasil.

2 USP São Carlos - São Carlos - São Paulo - Brasil.

* Autora correspondente: carolinesoler.mahotmail.com.
} 


\section{INTRODUÇÃO}

Um dos motivos pelos quais os reservatórios são construídos é o abastecimento de água. A erosão a montante de um reservatório deposita sedimentos na base do reservatório, o que diminui sua capacidade de armazenamento de água e, consequentemente, sua utilidade para esse propósito.

A movimentação de sedimentos para os corpos hídricos é uma consequência do intemperismo que ocorre nos acidentes geográficos, e pode ser acelerada por fatores mecânicos de acordo com as técnicas de manejo do solo usadas. Para tanto, o planejamento de conservação do solo e da água necessita de conhecimento das relações entre os fatores que causam a perda de solo e de água, e dos que ajudam a diminuir tais perdas (WINCHELL et al., 2013).

O objetivo principal deste trabalho foi simular a quantidade de sedimentos que chega num manancial de abastecimento público; como exemplo, este foi aplicado no Reservatório Bom Jardim, na cidade de Uberlândia em Minas Gerais.

O SWAT (Soil and Water Assessment Tool) é um modelo matemático que permite que diferentes processos físicos sejam simulados em escala de bacia hidrográfica. Tem o objetivo de analisar os impactos das alterações no uso e na ocupação do solo sobre o escoamento superficial e subterrâneo, produção de sedimentos e qualidade da água em bacias hidrográficas rurais e urbanas, onde a poluição difusa é a principal causa da degradação dos recursos hídricos (NEITSCH et al., 2005).

\section{REVISÃO BIBLIOGRÁFICA:}

De acordo com Maidment (1993), modelo hidrológico é a representação matemática do escoamento de água e seus constituintes em alguma parte da superfície do solo ou subsolo.
Os modelos de qualidade de água e os modelos hidrológicos apresentaram um desenvolvimento significativo nos últimos anos. Existem modelos que tratam apenas de alguns processos hidrológicos, como escoamento, chamado de modelos chuva-vazão, e outros modelos que envolvem diversos processos, como escoamento, transporte de sedimentos, crescimento vegetal, qualidade da água entre outros, os quais são mais complexos e envolvem um número maior de variáveis de entrada.

Vários modelos podem ser encontrados na literatura, onde a diferença entre cada um reside na resolução espacial e temporal de seus dados (BARROS, 2008).

O modelo AVGWLF (Arc View Generalized Watershed Loading Function Modelo) foi lançado em 1987 e vem sendo melhorado desde então. O modelo atual inclui a interface com o Arc View, sendo utilizado em diversas bacias hidrográficas nos Estados Unidos. É indicado para o planejamento de bacias hidrográficas onde os nutrientes e os sedimentos são as principais preocupações. Para o escoamento superficial e o aporte de sedimentos, são usadas a equação curva número (CN) e a equação de perda de solos (USLE), combinadas com concentração média de nutrientes, baseada no uso do solo (EPA, 2005).

O SWAT (Soil and Water Assessment Tool) é um modelo muito usado para simulações. Foi desenvolvido em 1996, nos EUA, pelo Serviço de Pesquisa Agrícola localizado na Universidade Texas A\&M. O SWAT incorpora grande parte dos avanços contidos em outros modelos hidrológicos e de qualidade de água, e objetiva predizer o impacto do uso e manejo do solo sobre o ciclo hidrológico, transporte de sedimentos e qualidade da água em bacias hidrográficas.

O SWAT é um modelo matemático que permite que diferentes processos físicos sejam simulados em escala de bacia hidrográfica. Tem o 
objetivo de analisar os impactos das alterações no uso e ocupação do solo sobre o escoamento superficial e subterrânea, produção de sedimentos e qualidade da água em bacias hidrográficas rurais e urbanas, onde a poluição difusa é a principal causa da degradação dos recursos hídricos (NEITSCH et al., 2005).

O estudo da erosão dos solos é muito importante sob os aspectos sociais e econômicos, uma vez que analisa as perdas de solo em terras agricultáveis e em outras áreas de interesse imediato, bem como pelos efeitos indiretos, como no assoreamento dos rios, lagos e reservatórios (DA SILVA et al., 2012). Com a aplicação de modelos hidrossedimentológicos que utilizam como dados de entrada imagens de alta e moderada resoluções espaciais é possível detectar mudanças no uso do solo e analisar a variabilidade espacial e temporal dos impactos causados pela ação antrópica no escoamento superficial e na produção de sedimentos (BRAGA et al., 2013).

As investigações e pesquisas envolvendo o uso de modelos hidrológicos ainda são limitadas em função do grande número de informações necessárias para descrever a variabilidade espacial e temporal dos sistemas naturais e da carência de dados detalhados referentes às variáveis de entrada nos modelos. Ainda assim, muitos trabalhos são executados com dados limitados e condições desfavoráveis. Algumas instituições públicas e privadas utilizam o SWAT para prognosticar problemas relacionados à erosão e assoreamento.

De acordo com revisão bibliográfica sobre desafios e perspectivas da aplicação do SWAT no Brasil, realizada por Bressiani et al. (2015), houve um crescimento do uso do modelo SWAT a partir do ano de 2009, aumento este que pode ser justificado pelas oficinas de treinamento sobre o modelo no Brasil e pelo site do SWAT ter possibilitado haver maior consciência sobre suas capacidades. Ainda nesta pesquisa, Bressiani et al.
(2015) identificaram que muitos dos estudos que utilizam o modelo têm o objetivo de obter a produção e o transporte de sedimentos.

Machado et al. (2003) aplicaram o modelo SWAT para simular a carga de sedimentos produzida pela microbacia hidrográfica do Ribeirão dos Marins, em Piracicaba (SP), entre 1999 e 2000. Os resultados obtidos na simulação da produção de sedimentos foram comparados com os dados observados em um posto hidrossedimentométrico, localizado no terço superior da microbacia. Também aplicaram o modelo na simulação de dois cenários alternativos de uso da terra, que geraram resultados para a validação do modelo.

A aplicação do modelo SWAT na bacia hidrográfica do ribeirão Lavrinha $\left(6,88 \mathrm{~km}^{2}\right)$, estudo realizado por Pinto (2011), mostrou-se adequada nas simulações de escoamento, tanto para simulações diárias como mensais, sinalizando sua aplicabilidade para pequenas bacias hidrográficas. No trabalho citado, o modelo também foi aplicado na simulação de diferentes cenários, comprovando-se sua eficácia e sensibilidade, tanto na avaliação da produção como no transporte de sedimentos. A substituição de pastagem por eucalipto, por exemplo, resultou na redução da produção de sedimentos. Em outro cenário simulado, adotou-se mata ciliar ao longo de toda a rede de drenagem, o que evidenciou a concentração de sedimentos na calha do curso de água analisado.

A avaliação da erosão do solo foi realizada por Barsanti et al. (2013) em duas bacias na área do Pantanal, localizado no Mato Grosso do Sul, com cenários de uso do solo distintos, alternando vegetação nativa por pastagem ou agricultura em um período de 30 anos. Foi observado que a erosão aumenta efetivamente com a diminuição da vegetação densa. Nessas circunstâncias, foram geradas estimativas que possibilitam a escolha 
de uma prática de manejo do uso do solo que minimizasse os danos ao meio ambiente.

Da Silva, et al. (2013) fizeram o uso do SWAT para uma bacia hidrográfica situada na Paraíba, com o objetivo de avaliar as taxas de erosão e a geração de escoamento em um reservatório; o estudo demonstrou a importância da cobertura do solo para a gestão da captação. Afirmam que as taxas de erosão estimadas podem não ser tão precisas, mas os resultados são úteis para determinar as áreas propensas à erosão e, assim, priorizar a intervenção nas mesmas, visto que as pesquisas de campo levariam muito tempo e teriam elevados custos financeiros.

De Aragão et al. (2013) mostram que o escoamento superficial foi incrementado por uma área mais antropizada e mais compactada devido à mecanização, por meio da aplicação do modelo SWAT à sub-bacia do Rio Japaratuba Mirim, em Sergipe, em seções de medição de estações de duas fazendas, visando à parametrização das duas bacias alinhadas por meio de processos de calibração e de validação. Foram realizadas simulações do escoamento na bacia menor, a partir dos parâmetros calibrados na bacia maior, e, reciprocamente, do escoamento na bacia maior. Os resultados também evidenciaram que o modelo calibrado simulou bem o escoamento superficial e conseguiu prever, de forma coerente, a produção de sedimentos.

Em outro estudo, Strauch, et al. (2013) analisaram o quanto as BMPs (Melhores Práticas de Gestão) podem contribuir para a gestão sustentável dos recursos hídricos em uma bacia hidrográfica chamada Pipiripau, localizada no Distrito Federal. Eles simularam pequenas bacias de retenção de sedimentos, terraceamento e rotação do sistema de plantação do milho e averiguaram que as técnicas de construção de pequenos bolsões de armazenamento de sedimentos, combinadas com técnicas de terraceamento, foram as que geraram maior redução da taxa de produção de sedimentos (40\%). Concluiu-se que as BMPs foram eficazes, e que seriam de semelhante eficácia para outras áreas de cultivo intensivo da região, incluindo bacias hidrográficas que drenam para reservatórios nos quais o assoreamento é uma grande preocupação.

Betrie et al. (2011) usaram o modelo SWAT para modelar a distribuição espacial do processo de erosão/produção de sedimento na Bacia "Upper Blue Nilo" em escala diária e avaliar o impacto de diferentes intervenções de manejo do solo na produção de sedimentos. Neste caso, utilizaram a proposição de cenários com aumento nas áreas de reflorestamento e as BMPs. O reflorestamento reduziu a produção de sedimentos tanto nas sub-bacias quanto nas saídas da bacia hidrográfica; no entanto, a eficácia de cada BMP foi dependente da porcentagem de terreno disponível e das condições topográficas locais na bacia. Concluíram, ainda, que o efeito das BMPs poderia ser potencializado por meio da implementação destas em conjunto com o reflorestamento em áreas íngremes.

Em estudo realizado por Emam et al. (2016) no distrito de Aluoi, localizado no centro do Vietnã, observou-se que o uso das BMPs diminui o escoamento superficial e consequentemente reduz a erosão do solo em terras agrícolas. Então, sugerem que sejam implementados sistemas de terraços e sistemas de contorno em terras íngremes, com o intuito de reduzir a produção de sedimentos.

Muitos dos estudos realizados demonstram que a falta de dados dificulta a realização das simulações; para isso, os resultados são tão precisos quanto a quantidade de dados que se inserem corretamente no modelo. Além disso, muitos trabalhos nacionais e internacionais sugerem práticas de manejo do solo e reflorestamento para reduzir a perda de solo, principalmente em terras agrícolas e áreas íngremes. 


\section{METODOLOGIA}

\subsection{Caracterização da área de estudo:}

A escolha do reservatório Bom Jardim para a execução prática do projeto se justifica pelo fato de este ser estratégico para a cidade de Uberlândia, visto que é responsável por $40 \%$ da água bruta utilizada para suprir a demanda de água da cidade.

A sub-bacia hidrográfica do ribeirão Bom Jardim (Fig. 1), que pertence à bacia hidrográfica do rio Uberabinha, está situada na região oeste do Estado de Minas Gerais (Mesorregião do Triângulo Mineiro), entre as coordenadas $18^{\circ} 36^{\prime}$ e $19^{\circ} 22^{\prime}$ de latitude Sul e $47^{\circ} 57^{\prime}$ e $48^{\circ} 33^{\prime}$ de longitude Oeste. A sub-bacia em estudo fica entre a região
Sul do município Uberlândia e Norte do município de Uberaba (MG).

O clima da região é tropical, com estação seca entre os meses de maio e outubro e estação úmida entre os meses de novembro e abril. $A$ área drenada pela bacia do Ribeirão Bom Jardim é de $397,35 \mathrm{~km}^{2}$ e seu perímetro de 108,848 km.

O Ribeirão Bom Jardim nasce próximo à rodovia BR-050, no município de Uberaba, percorrendo aproximadamente $40 \mathrm{~km}$ até a confluência com o rio Uberabinha, que se situa nas proximidades da área urbana de Uberlândia. Próximo à sua foz, localiza-se a represa de captação de água do Departamento de Águas e Esgoto do Município de Uberlândia - DMAE (BRITO; RODRIGUES, 2001).

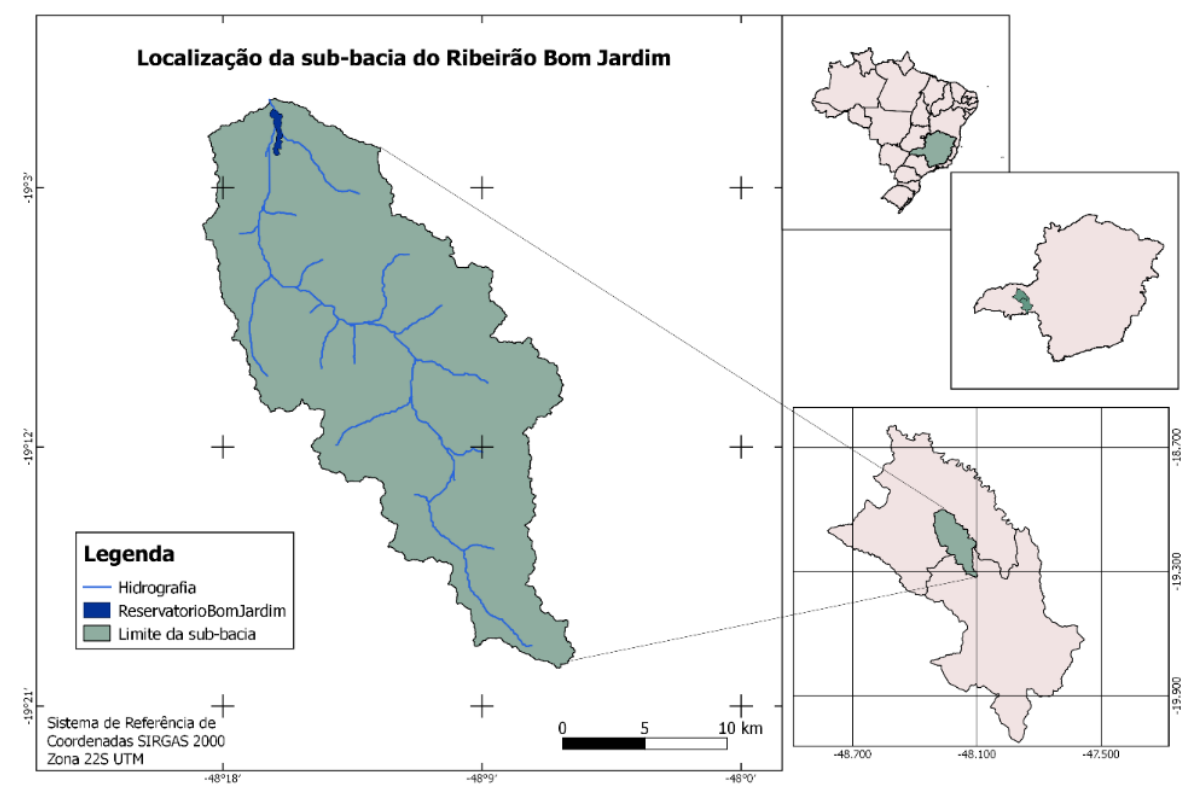

Figura 1. Localização da sub-bacia do Ribeirão Bom Jardim

\subsection{Modelo digital de elevação}

Utilizou-se o software SWAT com o intuito de obter dados sobre a produção de sedimentos na bacia de estudo. Para isso, inseriram-se no SWAT os dados referentes ao tipo de uso de solo, tipo de solo e o modelo digital de elevação (MDE) da área da sub-bacia do Ribeirão Bom Jardim, além de dados históricos de estações meteorológicas.

O modelo digital de elevação utilizado foi uma imagem radar, gerada a partir das imagens 
obtidas no site do Banco de Dados Geomorfométricos do Brasil, no projeto TOPODATA, que disponibiliza o Modelo Digital de Elevação para toda a região brasileira. Então fez-se o download dos dados de Altitude das quatro cartas da região de Uberlândia (MG) e Uberaba (MG), denominadas: 18S495, 18S48_, 19S495, 19S48_e construiu-se o modelo digital de elevação, por meio do mosaico e tratamento das imagens com resolução de $90 \mathrm{~m}$.

A partir do modelo digital de elevação, o SWAT gera a hidrografia da bacia, faz a delimitação das sub-bacias (Fig. 2) e posteriormente usa essas informações para gerar o mapa de declividade, de acordo com as classes de declividade escolhidas, conforme a inclinação presente no terreno (Tabela 1).
Tabela 1 - Classes de declividade adotadas

\begin{tabular}{|c|c|c|c|}
\hline Fases do Relevo & $\begin{array}{c}\text { Intervalos de } \\
\text { Declividade em \% }\end{array}$ & \multicolumn{2}{|c|}{ Área Ocupada } \\
\hline km² & $\%$ \\
\hline Plano & 0 a 3 & 169.88 & 42.63 \\
\hline Suave ondulado & $3 \mathrm{a} 8$ & 185.68 & 46.59 \\
\hline Ondulado & $8 \mathrm{a} 20$ & 42.27 & 10.6 \\
\hline Forte ondulado & $<20$ & 0.71 & 0.18 \\
\hline Total & & $\mathbf{3 9 8 . 5 4}$ & $\mathbf{1 0 0}$ \\
\hline
\end{tabular}

Assim, a partir do MDE e das classes inseridas, gerou-se um mapa de declividade do terreno e foram definidas 28 sub-bacias, conforme as informações características da área e da hidrografia gerada, sendo que o reservatório ficou totalmente inserido na sub-bacia 1 , como pode ser visto na Fig. 2. Dessa maneira, definiu-se que o aporte de sedimentos que chega ao reservatório é igual ao aporte de sedimentos acumulado que chega à sub-bacia 1 .

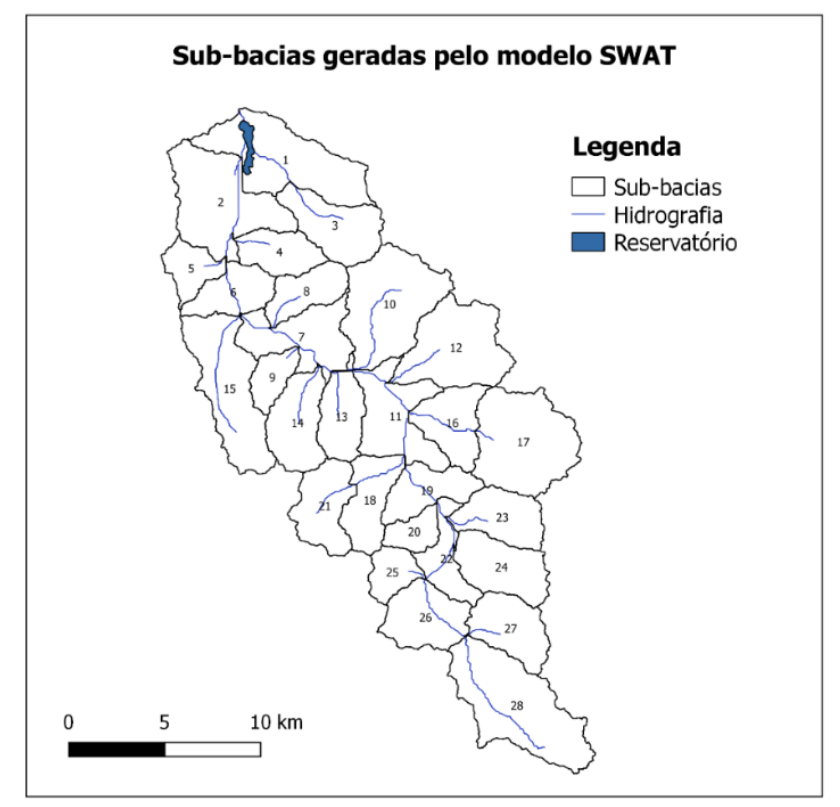

Figura 2. Sub-bacias do Ribeirão Bom Jardim geradas pelo modelo SWAT

\subsection{Tipo de solo}

O mapa de tipo de solos na região do Ribeirão Bom Jardim foi vetorizado no software ArcView na escala de 1:100.000, com base em levantamento realizado por Brito (2002), no qual a área da bacia apresenta basicamente dois tipos de solo: Latossolo e Neossolo, que são subdivididos em classificações mais específicas de acordo com as respectivas características, como pode ser visto na Fig. 3. 


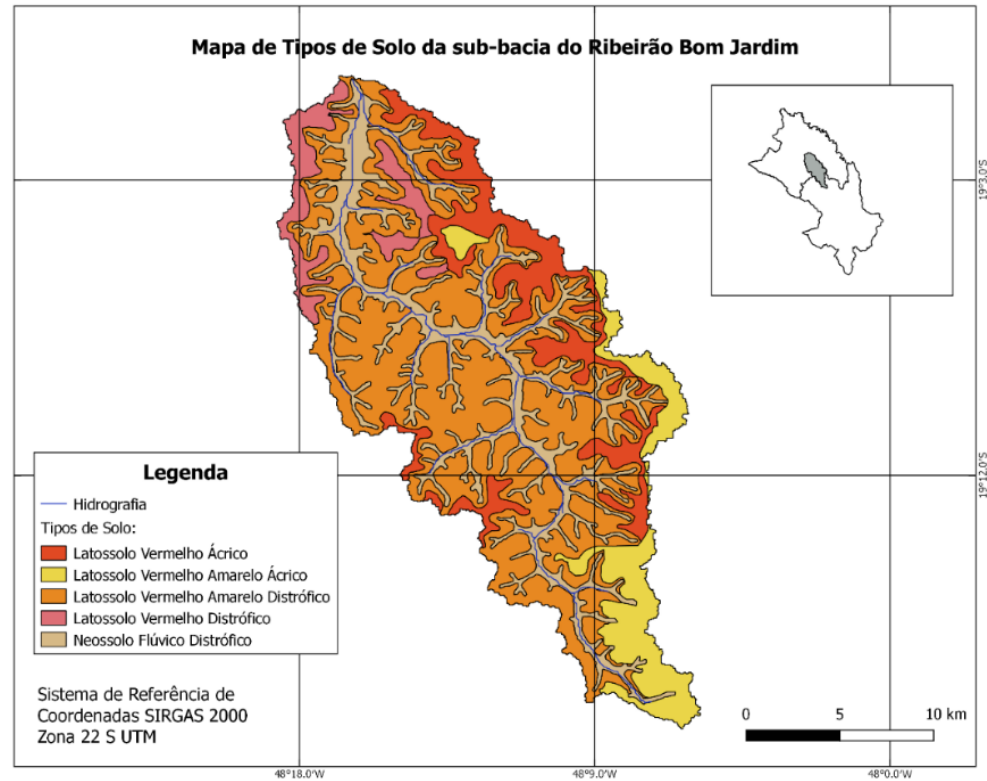

Figura 3. Tipo de Solos - Sub-bacia do Ribeirão Bom Jardim

Para inserir no banco de dados do modelo os diferentes tipos de solo presentes na sub-bacia, foi utilizada uma macro específica para o SWAT, chamada de arquivo de pedotransferência, que atua na geração de dados específicos sobre o solo, utilizando características básicas sobre o solo, neste caso resultantes de estudo feito por Brito (2002) na região de estudo.

\subsection{Uso do solo}

De acordo com Resende (2011), a bacia em estudo era recoberta originalmente pela vegetação de Cerrado, mas desde a década de 1970 iniciou-se o desmatamento da área, devido ao grande potencial de ser pioneira na expansão do agronegócio no Bioma Cerrado. Atualmente, o reservatório Bom Jardim é circundado por extensas áreas agrícolas, entrecruzadas por redes de estradas vicinais que podem constituir-se em caminhos preferenciais para sedimentos e demais substâncias transportadas pelo escoamento superficial.
De acordo com as atividades predominantes, classificou-se o uso do solo na região em cinco classes (Tabela 2), sendo elas: Agricultura, Pastagem, Campos hidromórficos, Água e Floresta. As áreas denominadas por "Agricultura" representam as culturas mais comuns da região de Uberlândia e Uberaba.

Tabela 2. Tipos de uso do solo

\begin{tabular}{|c|c|c|}
\hline \multirow{2}{*}{ Manejo do solo } & \multicolumn{2}{|c|}{ Área Ocupada } \\
\cline { 2 - 3 } & $\mathbf{k m}^{\mathbf{2}}$ & $\mathbf{\%}$ \\
\hline Agricultura & 255,64 & 64,336 \\
\hline Campos hidromórficos & 79,98 & 20,127 \\
\hline Pastagem & 39,96 & 10,057 \\
\hline Vegetação & 20,56 & 5,174 \\
\hline Água & 1,22 & 0,306 \\
\hline Total & $\mathbf{3 9 7 , 3 5 3 6}$ & $\mathbf{1 0 0}$ \\
\hline
\end{tabular}

A "Pastagem" representa as áreas com pasto destinadas à alimentação de gado. As áreas designadas como "Campos hidromórficos" são as áreas localizadas no entorno de cursos de água, com solos mais úmidos e presença de mata ci- 
liar em sua maioria. O tipo de solo "Floresta" caracteriza-se por florestas esparsas, áreas com reflorestamento ou vegetação nativa. O que é classificado como "Água" são todas as áreas nas quais há presença de cursos de água, incluindo o reservatório.

Para a elaboração do mapa de tipo de uso do solo (Fig. 4), foi utilizado o Sistema de Informações Geográficas QQGIS 2.18, de licença livre e distri- buído pela internet, e as imagens do satélite ResourceSat II, do mês de setembro de 2015, disponibilizadas pelo Instituto Nacional de Pesquisas Espaciais (INPE), na página <satélite.cptec.inpe. br> na internet.

As imagens foram georreferenciadas pelo Datum SIRGAS 2000 Zona 22S e classificadas de acordo com os usos propostos.

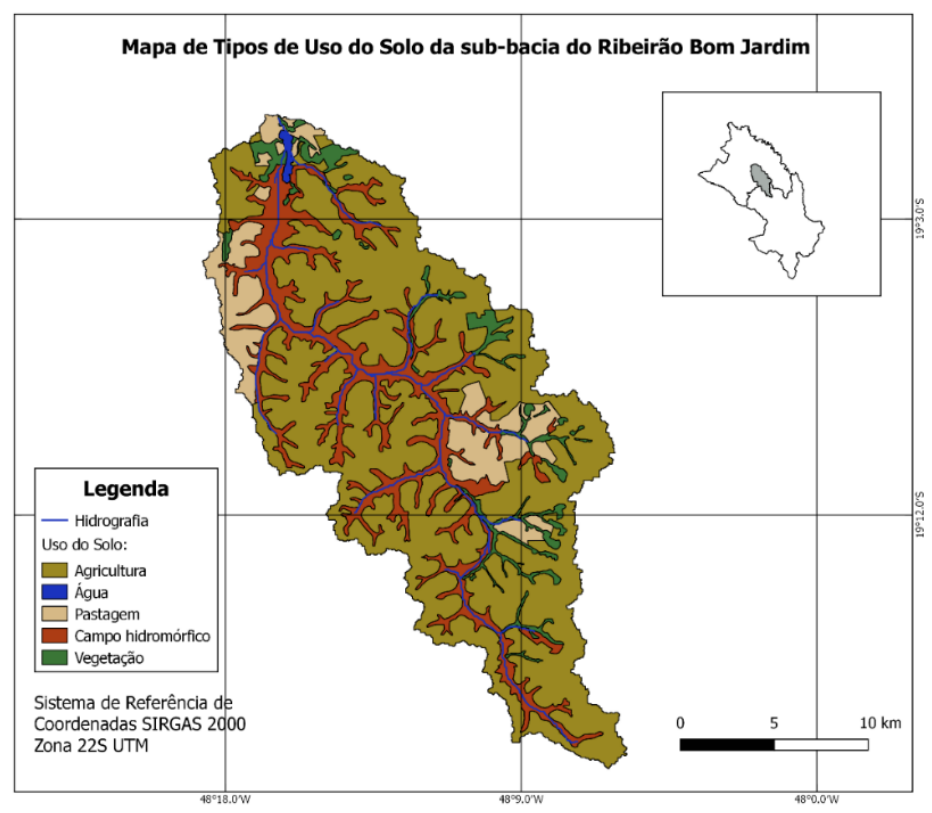

Figura 4. Mapa de tipo de Uso do Solo do Ribeirão Bom Jardim

Para a inserção dos dados de uso do solo no modelo, foi preciso associar o tipo de manejo presente na área a uma classe do banco de dados do SWAT que mais se aproximasse do real. Desta forma, foram utilizadas as seguintes classes (Tabela 3):

Tabela 3. Classes de uso do solo associadas às classes propostas pelo modelo

\begin{tabular}{|c|c|c|}
\hline \multirow{2}{*}{ Classes de uso do solo na sub-bacia } & \multicolumn{2}{|c|}{ Classes de Uso do Solo no banco de dados do } \\
SWAT
\end{tabular}


De acordo com o IBGE (2015), as culturas com maiores áreas presentes na região de Uberlândia e Uberaba são: soja, milho e cana-de-açúcar. Então, dividiu-se a área de agricultura entre essas três culturas, utilizando-se a proporção real, disponível pelos dados do IBGE. Nesse sentido, os valores adotados foram: $52 \%$ de soja, $25,5 \%$ de milho e $22,5 \%$ cana-de-açúcar.

\subsection{Parâmetros climáticos}

O banco de dados climáticos do modelo SWAT dispõe somente de informações características dos Estados Unidos. Portanto, para a área em estudo, fez-se necessário inserir dados climáticos diários para a sub-bacia hidrográfica do Ribeirão Bom Jardim. Contudo, a sub-bacia não contém estações meteorológicas em seu interior, então optou-se pela seleção das estações meteorológicas (Tabela 4) convencionais das cidades nas quais a sub-bacia está inserida: Uberlândia e Uberaba.

Tabela 4. Dados de localização das estações climatológicas

\begin{tabular}{|c|c|c|c|}
\hline Estação & Latitude $\left({ }^{\circ}\right)$ & Longitude $\left({ }^{\circ}\right)$ & Elevação (m) \\
\hline Uberlândia & -18.92 & -48.25 & 875 \\
\hline Uberaba & -19.73 & -47.95 & 737 \\
\hline Pastagem & 39,96 & 10,057 & \\
\hline Vegetação & 20,56 & 5,174 & \\
\hline Água & 1,22 & 0,306 & \\
\hline Total & 397,3536 & 100 & \\
\hline
\end{tabular}

O modelo requer dados diários de precipitação $\left(\mathrm{mm} \mathrm{H}_{2} \mathrm{O}\right)$, temperatura máxima e mínima do ar $\left({ }^{\circ} \mathrm{C}\right)$, radiação solar incidente $\left(\mathrm{MJ} \mathrm{m}^{-2} \mathrm{dia}^{-1}\right)$, velocidade do vento $\left(\mathrm{m} \cdot \mathrm{s}^{-1}\right)$ e umidade relativa do ar (\%).

A série histórica dos dados da estação meteorológica de Uberlândia foi cedida pelo Laboratório de Climatologia e Recursos Hídricos, pertencente ao Instituto de Geografia, da Universidade Federal de Uberlândia, que disponibiliza dados de precipitação, insolação, temperatura, vento e umidade relativa. Os dados da estação meteorológica de Uberaba foram conseguidos no banco de dados do INMET.

Para que a caracterização das médias climáticas fosse representativa, optou-se pelo uso de uma série histórica de 36 anos: 1981 a 2015, período que possuía o maior número de dados contínuos nas séries históricas comuns às duas estações. Por mais que o período escolhido tenha sido o de maior número de dados contínuos, ainda foram encontradas falhas, que não são aceitas pelo modelo. Então, para que estas fossem preenchidas, foi usado o Gerador Climático WXGEN (Weather Generator), um modelo gerador do estado atmosférico desenvolvido por Sharpley \& Williams (1990), que utiliza dados médios para gerar dados climatológicos diários e pode preencher falhas de dados.

\subsection{Aporte de sedimentos}

Optou-se por inserir diferentes cenários de uso e ocupação do solo no modelo. A primeira simulação representa o cenário real, com as culturas de milho, soja e cana-de-açúcar nas proporções reais em Uberlândia e Uberaba de acordo com o IBGE (2015), enquanto nas simulações posteriores fez-se alterações na área de Agricultura, substituindo-a por diferentes porcentagens de reflorestamento.

Após a inserção dos dados de entrada no modelo, são gerados os resultados sobre a produção de sedimento para cada cenário imposto. Nessas circunstâncias, é possível observar resultados dos cenários mais extremos e os mais conservacionistas (maiores áreas reflorestadas).

Então, pôde-se estimar o quanto cada uso do solo influencia no aporte de sedimentos que chega ao reservatório. 


\subsection{Coletas em campo}

Foram definidos 5 pontos ao redor do reservatório do Ribeirão Bom Jardim; os pontos 1, 2 e 3 estão localizados imediatamente a montante do reservatório. As coletas de sedimentos de fundo e as medições de vazão e das concentrações de sólidos suspensos, nestes três pontos, têm a função de levantar, respectivamente, a granulometria dos depósitos de fundo e as cargas de sedimentos em suspensão afluentes ao reservatório. Os pontos 4 e 5 localizam-se imediatamente a jusante do reservatório, sendo que neles foram levantadas as vazões e concentrações de sólidos suspensos com o propósito de conhecer as cargas de sedimentos efluentes ao reservatório.

Para determinação das concentrações de sólidos totais, sólidos dissolvidos e sólidos suspensos foram realizados os ensaios no Laboratório de Saneamento, localizado na Faculdade de Engenharia Civil da Universidade Federal de Uberlândia (FECIV - UFU). Para isso, foi utilizada a metodologia proposta pela Associação Brasileira de Normas Técnicas (ABNT): NBR 10664 Águas - Determinação de resíduos (sólidos) - Método gravimétrico.

Para a determinação da curva granulométrica das amostras de depósitos de fundo coletadas, foi utilizada a metodologia proposta pela ABNT: NBR 6457 de 1986 Amostras de Solo - Preparação para Ensaios de compactação e ensaios de caracterização, e em seguida foram utilizados ensaios propostos pela ABNT: NBR 7181 Solo - Análise Granulométrica. Esses ensaios foram realizados no Laboratório de Geotecnia da FECIV - UFU.

\subsection{Estimativa do volume do reservatório}

Com a carta planialtimétrica levantada pelo Exército brasileiro no ano de 1983, fez-se o modelo numérico de terreno, a partir do qual construiu-se uma macro do Excel que permitiu calcu- lar a área inundada e o volume acumulado para diferentes cotas. De uma forma geral, essa rotina computacional armazena as coordenadas e as cotas do modelo de terreno na forma de matrizes e verifica qual ponto está ao sul do contorno da barragem e, ao mesmo tempo, abaixo de uma cota de nível de água pré-fixada. Dessa forma, a área inundada e o volume de água acumulado podem ser estimados como:

$$
\begin{aligned}
& \Delta A i=\Delta x * \Delta y \quad \text { se } Z i \leq N A \\
& \Delta A i=0 \quad \text { se } Z i>N A \\
& A=\sum_{i=1}^{N} \Delta A i \\
& \Delta \text { Voli }=\Delta x * \Delta y *(N A-Z i) \quad \text { se } Z i \leq N A \\
& \Delta \text { Voli }=0 \quad \text { se } Z i>N A
\end{aligned}
$$

$\operatorname{Vol}_{\text {RES }}=\sum_{i=1}^{N} \Delta$ Voli

Nessas expressões, $\Delta x$ e $\Delta y$ representam os espaçamentos entre os nós do modelo numérico de terreno, nas direções Leste e Norte, respectivamente. NA é o valor pré-fixado para a cota do nível da água no reservatório, enquanto $Z i$ é a cota do terreno no nó $i$ do MNT. A diferença entre NA e Zi corresponde à profundidade do reservatório no referido nó. Note-se que, se o nível de água estiver abaixo do nível do terreno, os incrementos de volume $\Delta$ Voli não são computados. O volume final do reservatório $\left(V_{\text {Oo }} l_{\text {RES }}\right)$, para a superfície livre na cota $N A$ é, enfim, calculado como a soma dos volumes incrementais.

Para o cálculo do assoreamento de reservatórios, foi utilizado um programa desenvolvido por Maia et al. (2002), construído na linguagem Visual Basic e aplicado aos objetos do Excel. 
3.9 Índice de abatimento - ou de atenuação de assoreamento

Com os cenários de áreas de floresta incrementais, conjectura-se que haja reduções nas cargas de sedimentos gerados na sub bacia. Consequentemente deverá ser observada uma atenuação do assoreamento do reservatório, quando comparada com a situação real, na qual os cenários conservacionistas não foram aplicados. Uma forma de mensurar essa redução consiste no cálculo do índice de abatimento de assoreamento. Dessa maneira, o índice de abatimento leva em conta o volume assoreado que foi reduzido, em um intervalo de tempo, mediante a aplicação dos cenários conservacionistas. Nesse caso, tal índice pode ser calculado, genericamente, como:

$$
I A_{k}(\%)=\frac{\left(V o l_{1}-V o l_{k}\right)}{V o l_{1}} \times 100
$$

$\mathrm{Na}$ Eq. (5), $I A_{k}$ é o índice de abatimento de assoreamento, calculado em escala anual, enquanto $\mathrm{Vol}_{1}$ e Vol $\mathrm{k}_{\mathrm{k}}$ ão, respectivamente, os volumes de sedimentos depositados no reservatório, no cenário real e em um cenário $k$ qualquer. Com essa descrição, o índice de abatimento pode ser interpretado como a redução percentual do assoreamento, em comparação com o cenário real. Esse indicador é especialmente interessante em termos práticos, uma vez que permite vislumbrar, de forma simples, a magnitude dos benefícios ambientais provocados pela aplicação de um ou mais cenários conservacionistas.

\section{RESUlTAdOS E DISCUSSÃO}

A seguir, são apresentados os resultados referentes às simulações feitas com diferentes cenários, demonstrando o quão significativa é a substituição de Agricultura por Floresta na produção de sedimentos e no consequente aporte dos mesmos até o reservatório. No modelo SWAT, a quantidade de sedimentos que é transportada com a água por um canal em um determinado tempo é chamada de SED_IN e a média diária da vazão em um canal durante um espaço de tempo é nomeada FLOW_IN. Para isso, é correlacionada a produção de sedimentos (ton) e a vazão $\left(\mathrm{m}^{3} / \mathrm{s}\right)$, que chegam na sub-bacia 1 , na qual está inserido o reservatório Bom Jardim. Desta forma, adota-se que o aporte de sedimento contribuinte ao reservatório é igual ao SED_IN da sub-bacia 1. Essa variável é especialmente importante para a estimativa do assoreamento de reservatórios, uma vez que representa numericamente a massa de sedimentos afluentes durante um determinado intervalo de tempo. Nesse contexto, este trabalho adotou intervalos mensais, de forma que o aporte de sedimentos é estimado em toneladas por mês.

Curvas de aporte mensal de sedimentos em função da vazão média mensal são apresentadas na sequência. A Fig. 5 ( $A$ ) é referente aos cenários com substituição de pequenas porcentagens de Agricultura por Floresta, cenários estes que representam situações mais próximas à realidade, situações mais viáveis na prática, as quais poderiam ser adotadas por proprietários de terras na área da sub-bacia do Ribeirão Bom Jardim, caso haja alguma política de incentivo ao reflorestamento de áreas atualmente ocupadas por atividades agrícolas. A partir dos gráficos apresentados na Fig. 5, pode-se observar que houve diminuição no aporte de sedimentos de forma proporcional ao aumento da área de Floresta em substituição à Agricultura.

Nas simulações com cenários de 2, 4, 6, 8 e 10\% de Agricultura substituída por Floresta, a média de redução do aporte de sedimentos foi respectivamente de $0.56,1.12,1.65,2.17$ e $2.71 \%$.

Já a Fig. 5 (B) mostra substituições mais significativas na porcentagem de Agricultura por Flo- 
resta. Trata-se de cenários mais extremos, nos quais haveria troca de grandes áreas de cultivo por Floresta. Neste gráfico, tem-se as porcentagens de 10, 20, 30, 40, 50 e 100\% de agricul- tura por áreas verdes (Florestas). Tais mudanças resultaram em uma diminuição mais acentuada do aporte de sedimentos: $2.71,5.37,7.95,10.30$, 12.76 e $23,47 \%$ respectivamente.
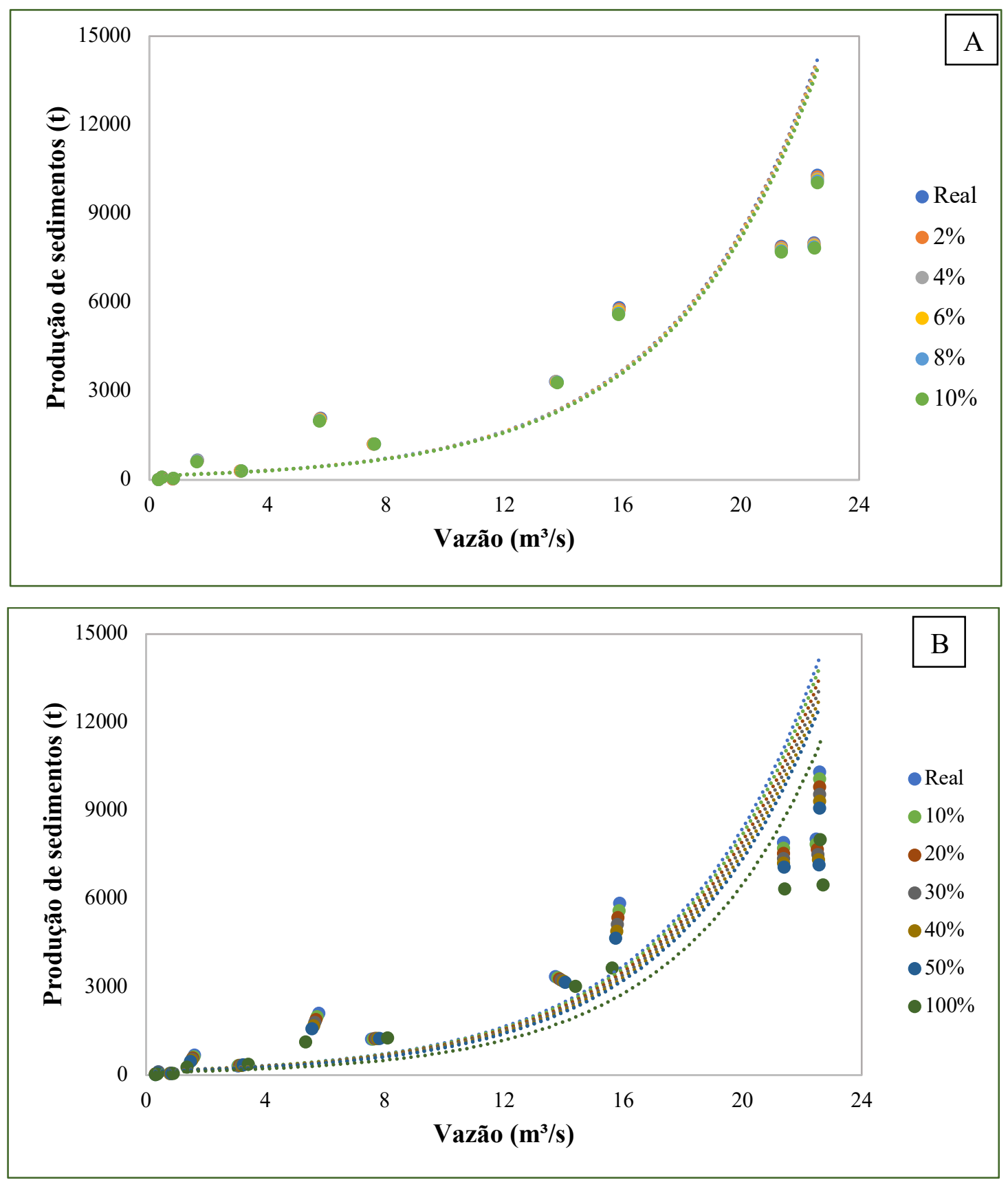

Figura 5 - Porcentagem de Agricultura substituída por Floresta no cenário Real

(A): Substituição de pequenas porcentagens de Agricultura por Floresta na sub-bacia.

(B): Substituição de porcentagens mais representativas de Agricultura por Floresta na sub-bacia. 
Pode-se afirmar assim que a diminuição da produção e o consequente aporte de sedimentos ao reservatório estão intimamente ligados à substituição de áreas de Agricultura por Floresta. Considerando a situação real, na bacia do Ribeirão Bom Jardim, $64.34 \%$ da área é ocupada por Agricultura, então, por menores que sejam as porcentagens de Agricultura substituída por Floresta, há atenuação na chegada de sedimentos ao reservatório. A despeito disso, essas reduções revelaram-se pouco expressivas para pequenos incrementos de área florestal, uma vez que atenuações no aporte superiores a $5 \%$ somente são conseguidas com mais de $20 \%$ da área de agricultura substituída por floresta. Quando estas variáveis são dispostas em um gráfico (Fig. 6) de dispersão, pode-se revelar uma tendência aparentemente linear entre elas.

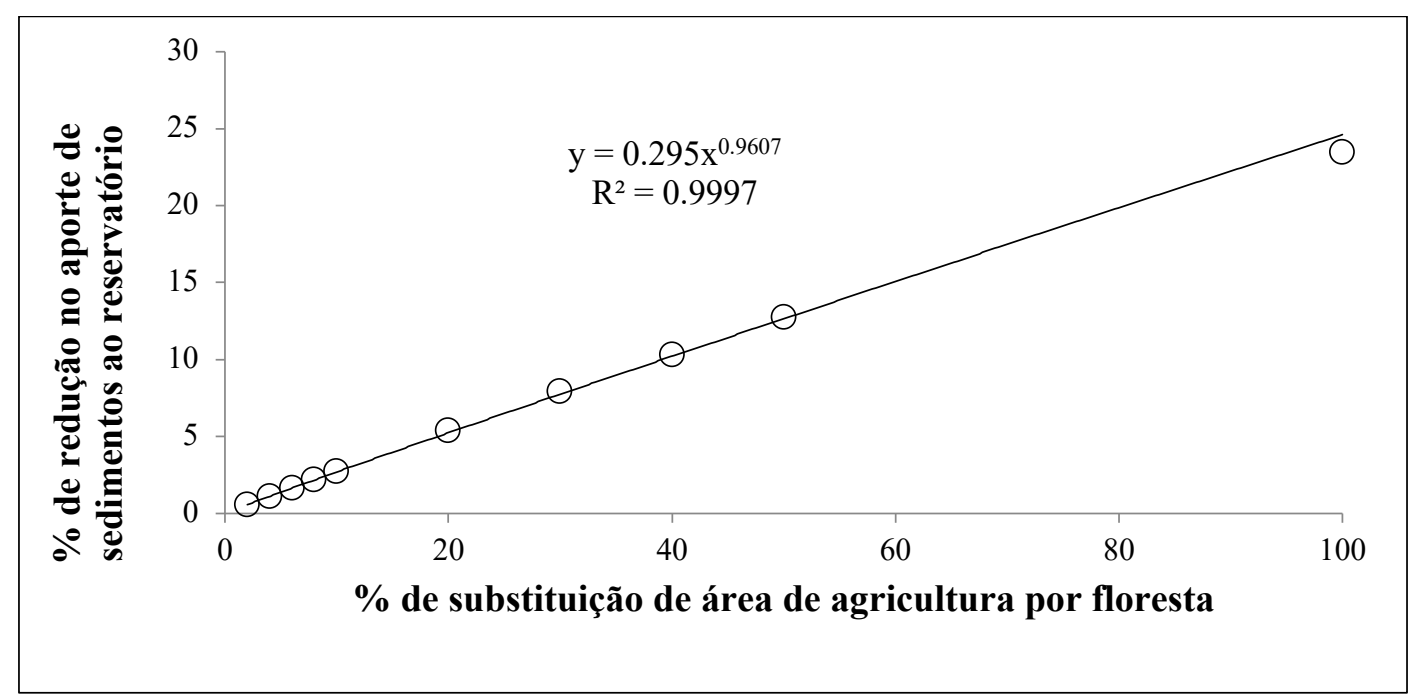

Figura 6 - Relações proporcionais entre a redução do aporte de sedimentos ao reservatório e a supressão da área de agricultura por floresta

Apesar do comportamento aparentemente linear, a linha de tendência que melhor representa as relações percentuais entre a redução do aporte de sedimentos ao reservatório e a supressão de áreas agrícolas com substituição por florestas é uma lei de potência dada pela seguinte expressão:

$y=0,295 \cdot x^{0,9607}$

$\mathrm{Na}$ Eq. 6, y é a porcentagem média de redução de aporte de sedimentos ao reservatório, enquanto $\mathrm{x}$ representa a porcentagem de área de agricultura substituída por reflorestamento. Essa expressão pode ser especialmente interessante para uso prático, diante da necessidade de uma previsão expedita da atenuação do aporte de sedimentos ao reservatório, em função do aumento de zonas reflorestadas na bacia analisada.

\subsection{Levantamentos de campo}

A descarga de massa é fisicamente definida como a massa de uma determinada substância, transferida por unidade de tempo. No contexto do presente estudo, o principal interesse consiste no levantamento das descargas de massa de sedimentos nos principais pontos de afluência ao reservatório do Bom Jardim, de maneira a indicar a quantidade de sedimentos que chega ao reservatório em um determinado intervalo de tempo. Essa variável foi estimada no item anterior, que 
apresentou valores de descargas mensais, com a variável SED_IN dada em toneladas por mês.

Neste item, são apresentados os resultados das campanhas de campo, com intuito de comparar os resultados estimados pelo modelo computacional, com resultados oriundos de medições instantâneas in loco. Os resultados das três campanhas de campo são apresentados na Tabela 5.

Tabela 5 - Resultados de vazão, concentração de sólidos totais e descargas de massa de sólidos

\begin{tabular}{|c|c|c|c|c|c|}
\hline Campanha & Data & Ponto & $\begin{array}{c}\text { Vazão medida } \\
\text { (m) } \mathbf{s} \text { ) }\end{array}$ & $\begin{array}{c}\text { Concentração } \\
\text { de sólidos totais } \\
\text { (mg/L) }\end{array}$ \\
\hline 1 & jun/2017 & 0,0308 & 1,18 \\
$\mathbf{d e s}$ sólidos (ton/dia)
\end{tabular}

A Fig. 7 mostra a espacialização dos 5 pontos, onde foram feitas as coletas de dados em campo, todos localizados no entorno do reservatório em análise.

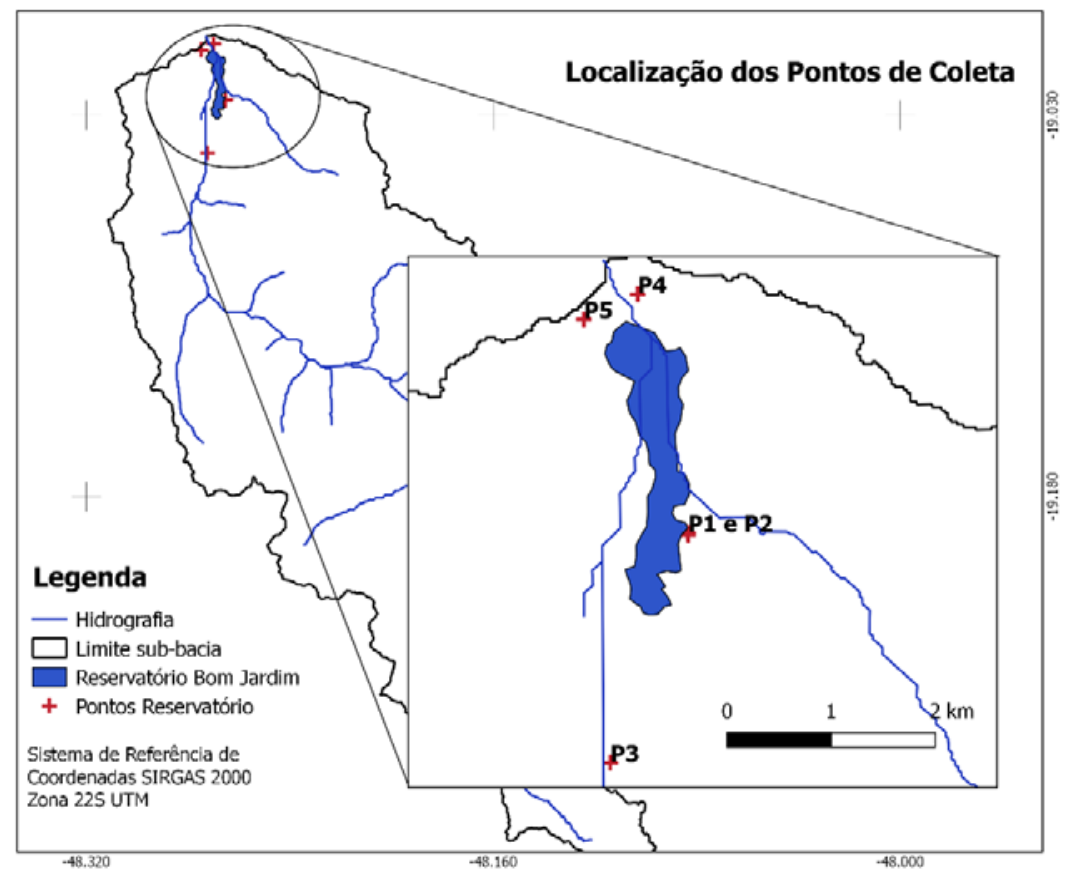

Figura 7 - Pontos de Coleta no entorno do Reservatório Bom Jardim 
Os pontos 1, 2 e 3 indicam seções afluentes ao reservatório do Bom Jardim. Nota-se que as maiores descargas de sedimentos afluentes ocorrem no ponto 3 , que se refere a uma seção transversal do curso de água principal (Ribeirão Bom Jardim) a montante do reservatório. Os pontos 1 e 2 apresentam descargas secundárias pelo afluente direto ao reservatório (córrego da Enxada), cujas descargas de massa resultaram em valores com ordem de grandeza menores do que no ponto 3 . Salienta-se que todas as medições aqui apresentadas foram realizadas em período de estiagem, o que justifica os valores inexpressivos das descargas de massa dos afluentes 1 e 2, uma vez que suas vazões foram pequenas. A pequena massa de dados, resultante de apenas três coletas, ainda não permite respostas conclusivas sobre o comportamento da descarga de sólidos afluentes ao reservatório, em função da vazão, relação conhecida como curva-chave de sedimentos. De fato, esse comportamento exige dados mais numerosos, o que somente será possível com coletas sistemáticas que, embora em andamento, fogem do escopo do presente trabalho.

Comportamentos inconclusivos também são indicados pelas descargas efluentes ao reservatório, verificadas nos pontos 4 e 5 . Na campanha de junho/2017, medições no ponto 5 , no canal de derivação que interliga o reservatório à estação de captação de água, registraram concentrações elevadas de sólidos que resultaram em descarga de massa exagerada e duvidosa, uma vez que grande parte do sedimento deveria ser retida no reservatório. Como este ponto situa-se aproximadamente $500 \mathrm{~m}$ a jusante da comporta por onde a água é retirada do reservatório, optou-se por deslocar o ponto 5 para uma seção imediatamente após essa comporta, de forma a capturar com mais exatidão a saída de sedimentos para este canal. Essa alteração foi realizada nas campanhas de outubro/2017 e novembro/2017, o que resultou em valores de concentração uma ordem de grandeza menores do que na campa- nha de junho/2017. Esse comportamento provavelmente é mais verossímil, haja vista que registrou descargas de sedimentos inferiores à soma das descargas de entrada no reservatório.

No ponto 4, as descargas de sólidos medidas em junho/2017 superaram os registros do mesmo ponto, medidas nas duas campanhas seguintes. Essa superação em uma ordem de grandeza ainda não permite concluir sobre a confiabilidade do dado de junho/2017, o que ratifica a importância de demais campanhas de campo.

Além disso, é importante frisar que o experimento para cálculo de sólidos em laboratório pode gerar uma gama de erros, visto que pode haver perda de compostos na evaporação e na calcinação, além de ganho de massa pela oxidação; sendo assim, é um método passível de erros (NBR 10664). A tendência é que tais imprecisões sejam potencializadas quando as concentrações de sólidos são pequenas, o que naturalmente ocorre nos períodos de estiagem.

Durante as campanhas de campo, sedimentos de fundo foram coletados nos pontos 2 e 3 , situados imediatamente a montante do reservatório, com intuito de obter a granulometria dos depósitos. A curva granulométrica encontrada para os dois tipos de depósitos analisados, referente às três visitas a partir dos ensaios de Análise Granulométrica, encontram-se na Fig. 8.

Para a construção da curva de granulometria foram detectadas parcelas dos depósitos que fazem parte de cada fração: areia grossa, média ou fina, argila e silte. Esses resultados revelam que, no ponto 2 , a maior parte dos sedimentos é composta por areia média, enquanto no ponto 3 a maioria é areia fina. Em ambos os pontos, as frações de silte e areia são ínfimas e não perfazem sequer $10 \%$ da amostra total. É interessante comentar que o ponto 2 consiste numa vereda, situada na confluência do córrego da Enxada com o reservatório do Bom Jardim e que, por 
isso, está praticamente dentro do reservatório. Como o ponto 3 é uma seção com características de rio, entende-se que o sedimento colhido no ponto 2 representa, com mais semelhança, os sedimentos depositados no fundo do reservatório. Em todo caso, a área drenada pelo ponto 2 é pequena diante daquela drenada pelo ponto 3. Em outras palavras, o sedimento que passa pelo ponto 3 representa com maior abrangência os sedimentos gerados na bacia de contribuição ao reservatório. Como todas as curvas indicam sedimentos com frações arenosas nitidamente predominantes, optou-se por utilizar uma curva granulométrica média para as futuras estimativas de assoreamento do reservatório. Assim, em termos médios, os depósitos de sedimentos são constituídos por $96,71 \%$ de areia, $2,23 \%$ de silte e $1,06 \%$ de argila.

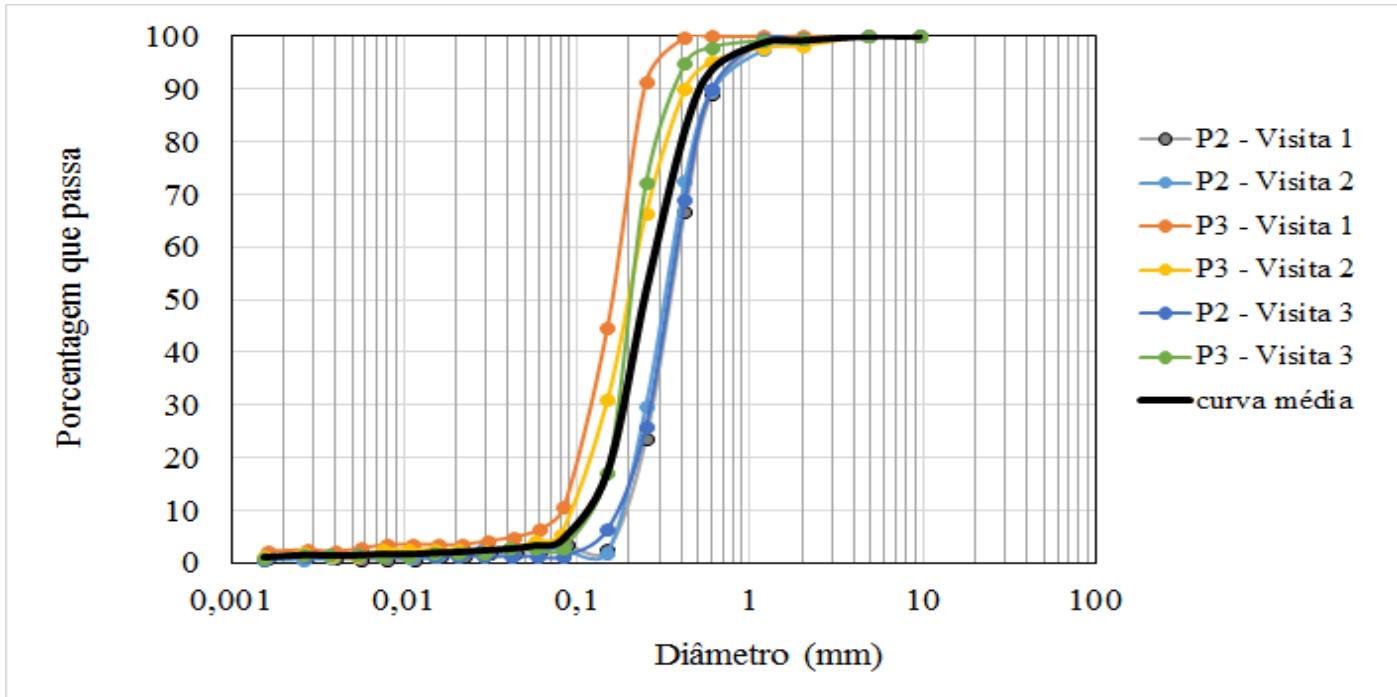

Figura 8 - Curva Granulométrica dos depósitos coletados nos pontos P2 e P3

\subsection{Cota-volume do reservatório}

Com base na metodologia descrita anteriormente, foi possível reconstruir as curvas cota-volume e cota-área inundada do reservatório do Bom Jardim. Salienta-se que, na ausência de batimetria, essa estimativa fundamentou-se em mapas planialtimétricos confeccionados antes da existência do reservatório. Assim, a fixação de diversas cotas para o nível da água e sua comparação com as cotas advindas do modelo numérico de terreno possibilitaram a obtenção de tais curvas, as quais são ilustradas pela Fig. 9.
A partir de comparações com o contorno do reservatório, obtido a partir de imagens aéreas, a cota do nível de água máximo foi considerada como $804 \mathrm{~m}$, o que representa um volume acumulado de $7,30 \mathrm{hm}^{3}$. Para efeito de cálculo de assoreamento, este foi considerado como o volume máximo normal do reservatório. As campanhas hidrométricas de campo, realizadas em outubro/2017 e novembro/2017, identificaram que a profundidade do canal de derivação (ponto 5) é de $2 \mathrm{~m}$, para um nível de água aproximadamente $1 \mathrm{~m}$ abaixo do nível superior das comportas. Com esse raciocínio, fixou-se a cota do nível de água mínimo operacional igual a $801 \mathrm{~m}$. 


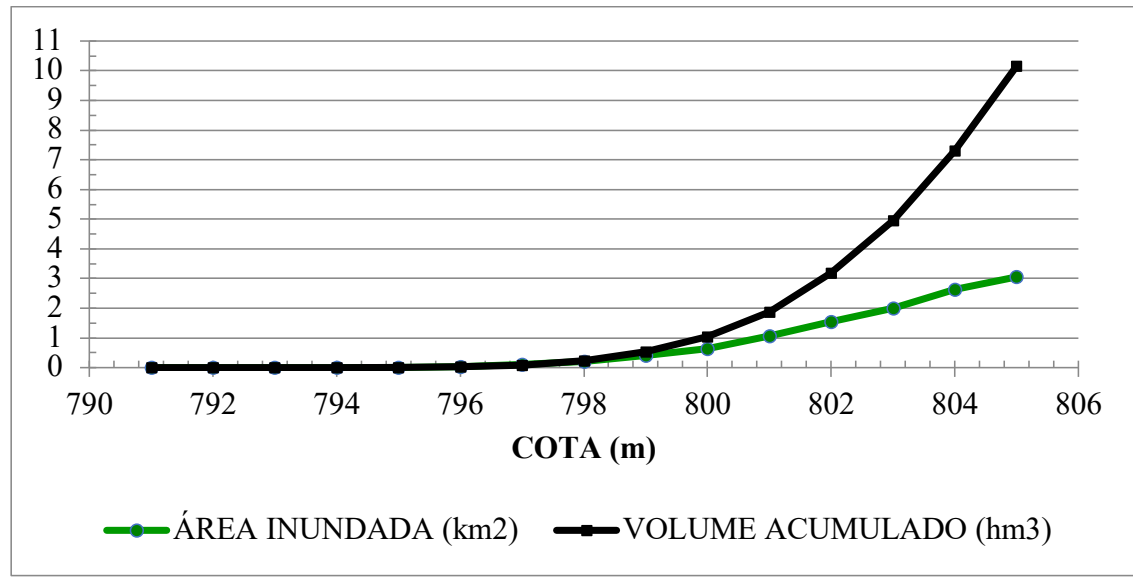

Figura 9 - Curvas cota-volume e cota-área inundada calculadas para o reservatório do Bom Jardim

\subsection{Estimativa do assoreamento do reservatório}

Para utilização do modelo de assoreamento foram necessários dados de aporte de sedimentos, de vazões afluentes gerados pelo modelo SWAT, além dos valores de vazão, da curva-chave de sedimentos afluentes ao reservatório Bom Jardim. As curvas-chave representam a relação entre a descarga de massa de sedimentos e a vazão afluente, variáveis cujos comportamentos foram estimados, para cada cenário de uso do solo, pelos gráficos apresentados no item 4.3 deste capítulo. A única diferença é que o modelo computacional para a previsão de assoreamento requer que as descargas sejam calculadas em toneladas por dia e não em toneladas mensais, conforme as estimativas originais pelo SWAT. Essas curvas são determinantes para a predição da quantidade de sedimentos que se acumula no fundo do reservatório ao longo dos anos.

Resumidamente, para uma dada vazão afluente, quanto mais inclinadas forem as retas que tangenciam esta curva, maior será o aporte de sedimentos e maior o potencial de se formarem depósitos de fundo que reduzem o volume do reservatório. Por isso, usos do solo que levam a maiores aportes de partículas fatalmente condicionarão assoreamentos mais acelerados. Nesse contexto, a curva-chave de sedimento, utilizada na simulação do cenário Real, é apresentada pela Fig. 10, a seguir.

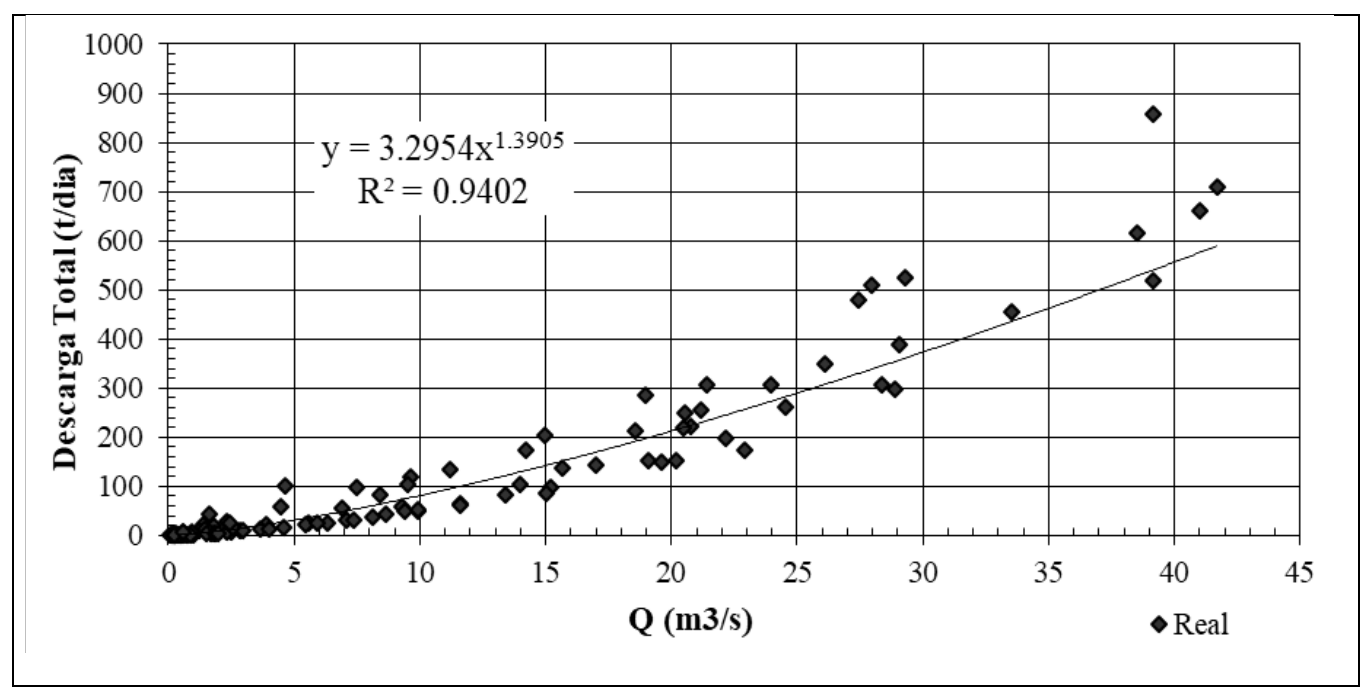

Figura 10 - Curva-chave de sedimentos afluentes ao reservatório para o cenário Real 
Com a aplicação do modelo computacional, foi feito o cálculo do assoreamento de reservatórios, que permitiu quantificar, aproximadamente, a redução do volume do sistema com o passar do tempo. A partir do cálculo do assoreamento, foi obtido o Índice de Abatimento Anual do Assoreamento do reservatório (\%), pelo qual é possível visualizar facilmente quantos por cento de abatimento anual do assoreamento do reservatório Bom Jardim, certa área de reflorestamento gera, seja ela de Agricultura (Fig. 10).

Na Fig. 11, é possível ver que, com $100 \%$ de reflorestamento das áreas da sub-bacia ocupadas por Agricultura, haveria um abatimento de quase $24 \%$ do assoreamento no reservatório Bom Jardim

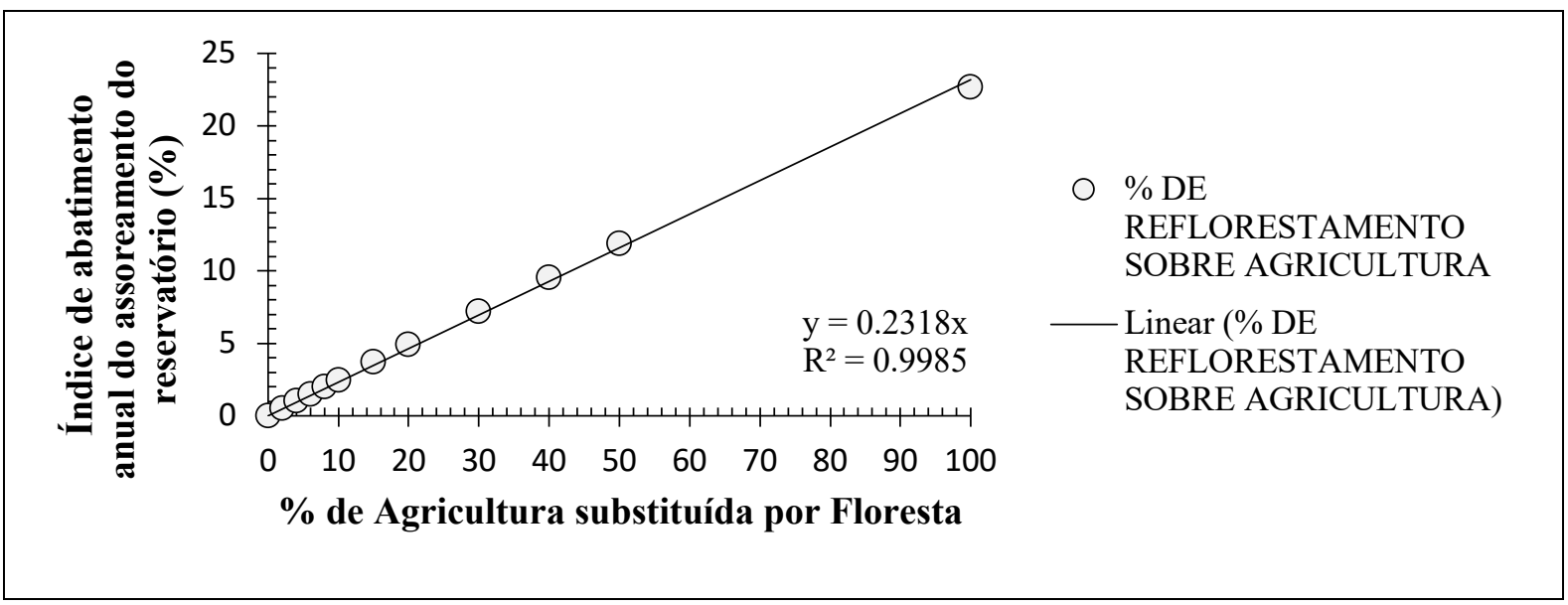

Figura 11 - Índice de Abatimento Anual do assoreamento do reservatório

\section{CONCLUSÃO}

$\mathrm{O}$ aporte de sedimento contribuinte ao reservatório (SED_IN da sub-bacia 1) reduziu-se com as substituições de diversas porcentagens de Agricultura por Floresta, variando de 0,56\% a $23,47 \%$, com as substituições de 2 e $100 \%$ respectivamente.

O assoreamento do reservatório seguiu o comportamento esperado de acordo com os resultados de SED_IN, ou seja, houve maior assoreamento no Reservatório para o cenário Real, seguido dos cenários com pouca substituição de Agricultura por Floresta, enquanto os cenários com grandes porcentagens de substituição de Agricultura por Floresta geraram grande redução no assoreamento, chegando a 22,6 e $6,9 \%$ respectivamente.
Tais abatimentos mostram quão importante são as reduções de áreas de Agricultura e por Florestas, o que poderia ser implantado em função de ações como o Pagamento por Serviços Ambientais (PSA), que traria benefícios diretos para a terra dos proprietários, tratando-se de melhor conservação dos recursos naturais das propriedades e benefícios indiretos para toda a população, como o menor assoreamento do reservatório Bom Jardim, que influencia o abastecimento público da cidade de Uberlândia - MG.

\section{AGRADECIMENTOS}

Os autores agradecem à Fundação de Amparo à Pesquisa do Estado de Minas Gerais (Fapemig) pelo apoio financeiro concedido ao projeto "Ges- 
tão de Reservatórios: incentivos aos serviços ambientais para a sustentabilidade dos regimes hidrossedimentológicos", processo TEC - APQ02097-14, edital Demanda Universal 01/2014.

\section{CONTRIBUIÇÃO DOS AUTORES}

Todos os autores contribuíram de forma igualitária.

\section{REFERÊNCIAS}

ASSOCIAÇÃO BRASILEIRA DE NORMAS TÉCNICAS. NBR: 6457 Amostras de Solo - Preparação para Ensaios de compactação e ensaios de caracterização. Rio de Janeiro, 1986.

ASSOCIAÇÃO BRASILEIRA DE NORMAS TÉCNICAS. NBR: 7181 Solo - Análise Granulométrica. Rio de Janeiro, p. 13. 1984.

ASSOCIAÇÃO BRASILEIRA DE NORMAS TÉCNICAS. NBR: 10664 Águas - Determinação de resíduos (sólidos) - Método Gravimétrico. Rio de Janeiro, p. 7. 1989.

BARROS, A. M. L. Modelagem da poluição pontual e difusa: aplicação do modelo MONERIS à bacia hidrográfica do rio Ipojuca, Pernambuco, 2008.

BARSANTI, P.; DISPERATI, L.; MARRI, P.; MIONE, A. Soil erosion evaluation and multitemporal analysis in two Brazilian basins. In INTERNATIONAL SWAT CONFERENCE (Vol. 2), 2013. Anais...

BETRIE, G. D.; MOHAMED, Y. A.; VAN GRIENSVEN, A.; \& SRINIVASAN, R. Sediment management modelling in the Blue Nile Basin using SWAT model. Hydrology and Earth System Sciences, 15(3), 807, 2011.

BRAGA, A. C. F. M.; DA SILVA, R. M.; SANTOS, C. A. G.; GALVÃO, C. de O.; NOBRE, P. Downscaling of a global climate model for estimation of runoff, sediment yield and dam storage: A case study of Pirapama basin, Brazil. Journal of hydrology, 498, 46-58, 2013.

BRASIL, IBGE. Produção Agrícola - Lavoura Temporária, 2015. Disponível em https://www.ibge.gov.br/. Acesso: novembro de 2017.

BRESSIANI, D. A.; D., GASSMAN, P. W., FERNANDES, J. G., GARBOSSA, L. H. P., SRINIVASAN, R., BONUMÁ, N. B., \& MENDIONDO, E. M. Review of soil and water assessment tool (SWAT) applications in Brazil: Challenges and prospects, 2015. International Journal of Agricultural and Biological Engineering, 8(3), 9.

BRITO, J. L. S. Os solos da bacia do ribeirão Bom Jardim e suas relações com relevo e os recursos hídricos, Uberlândia (MG), 2002. Revista Caminhos de Geografia 3(7), 2002.

BRITO, J.L.S.; RODRIGUES, S. C. Mapeamento geomorfológico de detalhe: uma proposta de associação entre o mapeamento tradi- cional e as novas técnicas em geoprocessamento. p. 1-7. Revista Eletrônica: Caminhos De Geografia, vol 1, ano 2. IGUFU, 2001.

DA SILVA, R. M.; MONTENEGRO, S. M. G. L.; SANTOS, C. A. G. Integration of GIS and remote sensing for estimation of soil loss and prioritization of critical sub-catchments: a case study of Tapacurá catchment. Natural Hazards, v. 62, n. 3, p. 953-970, 2012.

DA SILVA, R. M.; SANTOS, C. A. G.; SILVA, V. C. de L.; SILVA, L. P. Erosivity, surface runoff, and soil erosion estimation using GIS-coupled runoff-erosion model in the Mamuaba catchment, Brazil. Environmental monitoring and assessment, 185(11), 8977-8990, 2013.

DE ARAGÃO, R., CRUZ, M. A. S.; DE AMORIM, J. R.A.; MENDONÇA, L.C., DE FIGUEIREDO, E. E; SRINIVASAN, V. S. Análise de sensibilidade dos parâmetros do modelo SWAT e simulação dos processos hidrossedimentológicos em uma bacia no agreste nordestino. Revista Brasileira de Ciência do Solo, 37(4), 2013.

EMAM, A. R.; KAPPAS, M.; NGUYEN, L. H. K.; RENCHIN, T. Hydrological Modeling in an Ungauged Basin of Central Vietnam Using SWAT Model, Hydrology and Earth System Sciences, 2016.

EPA. United States Environmental Protection Agency. Handbook for Developing Watershed Plans to Restore and Protect Our waters. EPA 841-B-05-005: Washington, 2005.

MACHADO, R. E.; VETORAZZI, C. A.; XAVIER, A. C. Simulação de cenários alternativos de uso da terra em uma microbacia utilizando técnicas de modelagem e geoprocessamento. Revista Brasileira de Ciência do Solo, v. 27, n. 4, p. 727-733, 2003.

MAIA, A. G., ALAMY FILHO, J. E., DE SOUZA, L. B. S., VILLELA, S. M., \& SCHULZ, H. E. Método simplificado para estimativa do volume assoreado de reservatórios, 2002.

MAIDMENT, D. R. GIS and hydrologic modeling. In: GOODCHILD, M. F.; PARKS, B.O.; STEYAERT, L. T. (Ed.). Environmental modeling with GIS. New York: Oxford University, 1993. P. 147-167.

NEITSCH, S. L.; ARNOLD, J. G.; KINIRY, J. R.; \& WILLIAMS, J. R. Soil and water assessment tool theoretical documentation version 2005. Temple: Blackland Research Center, 2005. 541p.

PINTO, D. B. F. Aplicação do modelo SWAT (Soil and Water Assesment Tool) na simulação hidrossedimentológica em bacia hidrográfica da Serra da Mantiqueira, MG. 2011. Tese (Doutorado). Universidade Federal de Lavras (UFLA).

RESENDE, T. M. Conversão de uso e potencial de estoque do carbono nos diferentes usos do solo e cobertura vegetal na bacia do Ribeirão Bom Jardim no Triângulo Mineiro (MG). 2011.

SHARPLEY, A. N., WILLIAMS, J. R. Erosion Productivity Impact Calculator, 1. Model documentation (EPIC). U.S. Department of Agriculture, Agricultural Research Service, Tech. Bull, 1990.

STRAUCH, M.; LIMA, J. E.; VOLK, M.; LORZ, C.; MAKESCHIN, F. The impact of Best Management Practices on simulated streamflow and sediment load in a Central Brazilian catchment. Journal of environmental management, 127, S24-S36, 2013. 